\title{
Analisis Pengiriman Data Pada Jaringan Sensor Nirkabel Menggunakan Modul Xbee Dan Wemos
}

\author{
Asmah Akhriana \\ Program Studi Teknik Informatika \\ STMIK Dipanegara \\ Makassar, Indonesia \\ rhyna.akhriana@gmail.com \\ Muh. Ikrimah Hidayat \\ Program Studi Teknik Informatika \\ STMIK Dipanegara \\ Makassar, Indonesia \\ ikrimahhidayat@gmail.com
}

\author{
Irsal \\ Program Studi Teknik Informatika \\ STMIK Dipanegara \\ Makassar, Indonesia \\ irsal@dipanegara.ac.id \\ Inkasari \\ Program Studi Teknik Informatika \\ STMIK Dipanegara \\ Makassar, Indonesia \\ inkasari110@gmail.com
}

\begin{abstract}
Abstrak - Perkembangan teknologi jaringan sensor nirkabel (JSN) mengalami kemajuan yang sangat pesat pada belakangan ini. Perkembangan tersebut juga memicu berkembangnya modul wireless yang digunakan dalam JSN. Modul Xbee dan Modul Wemos merupakan modul wireless yang sering digunakan untuk merancang jaringan sensor nirkabel. Xbee menggunakan standar Zigbee 802.15.4 sedangkan Modul Wemos menggunakan standar WiFi $802.11 \mathrm{~b} / \mathrm{g} / \mathrm{n}$. Dalam penelitian ini akan dilakukan analisis kinerja pengiriman data antara Modul Xbee dan Modul Wemos. Perbandingan dilakukan dengan cara menguji Jarak Pengiriman dan delay dalam kondisi LOS (line of sight) dan NLOS (None line of sight). Data input yang digunakan dalam penelitian ini adalah suhu dari minyak goreng yang dipanaskan dan dideteksi dengan menggunakan sensor termokopel yang ditampilkan pada LCD sebagai Output. Dari hasil penelitian, jarak maksimal pengiriman data pada kondisi LOS (line Of Sight) tanpa repeater untuk modul Xbee yaitu 140 meter dengan delay 5 detik sedangkan modul Wemos yaitu 70 meter dengan delay 5 detik. Sedangkan jarak maksimal pada kondisi LOS dengan menggunakan repeater untuk modul Xbee yaitu 280 meter dengan delay 6 detik dan modul Wemos yaitu 140 meter dengan delay 7 detik. Hasil Pengujian Jarak Maksimal pengiriman data pada kondisi NLOS (None line Of Sight) tanpa repeater untuk modul Xbee yaitu 25 meter dengan delay 6 detik sedangkan modul Wemos yaitu 15 meter. Sedangkan jarak maksimal pada kondisi NLOS dengan menggunakan repeater untuk modul Xbee yaitu 50 meter dengan delay 6 detik dan modul Wemos yaitu 30 meter. Hasil penelitian ini dapat digunakan oleh masyarakat sebagai salah satu referensi dalam memilih modul wireless apa yang cocok untuk keperluan yang dibutuhkan dalam membangun jaringan sensor nirkabel.
\end{abstract}

Kata Kunci-Jaringan Sensor Nirkabe (JSN), Xbee, Wemos, Termokopel, Line of Sight (LOS)

\section{PENDAHULUAN}

Perkembangan teknologi komunikasi dan informasi saat ini berkembang dengan sangat pesat yang dapat memungkinkan layanan komunikasi jarak jauh tanpa menggunakan kabel yang disebut dengan teknologi nirkabel yang sudah merambah ke segala aspek kehidupan manusia dari bidang industri hingga ke rumah tangga, salah satunya adalah jaringan sensor nirkabel (JSN). Jaringan sensor nirkabel adalah teknologi nirkabel yang terdiri dari kumpulan node sensor yang tersebar di suatu area tertentu dimana tiap node sensor memiliki kemampuan untuk mengumpulkan data dan dapat berkomunikasi dengan node sensor lainya [1]. Dengan adanya JSN, dapat dibuat sistem untuk melakukan pengukuran suhu, kelembaban, tekanan, kecepatan aliran, ketinggian cairan dan sebagainya. Pengukuran dilakukan oleh node sensor, kemudian node sensor mengirimkan informasi ke base-station untuk diolah kembali.

Manfaat jaringan sensor nirkabel dalam bidang industry contohnya pada PLN dimana memanfaatkan jaringan sensor nirkabel untuk memantau suhu minyak pada trafo agar dapat meminimalisir terjadinya ledakan pada PLN karena petugas PLN dapat mengetahui apabila suhu minyak trafo terlalu panas, PLN dapat juga menghemat biaya karena tidak perlu menggunakan banyak kabel dalam pemasangan alat. Sedangkan untuk manfaat jaringan sensor nirkabel dalam bidang rumah tangga yaitu sebagai alternatif solusi untuk menjaga dan mengawasi rumah menggunakan teknologi jaringan sensor nirkabel sehinggan pemilik rumah tetap dapat mengawasi keadaan rumah dari jarak jauh dan masih banyak lagi manfaat dari jaringan sensor nirkabel.

Teknologi nirkabel yang diterapkan dalam JSN antara lain modul Xbee dan Wemos D1 mini. Dua modul ini menggunakan standar yang berbeda 
yaitu , Xbee menggunakan standar Zigbee 802.15.4 [2] sedangkan Wemos menggunakan standar WiFi $802.11 \mathrm{~b} / \mathrm{g} / \mathrm{n}$ dimana kedua modul wireless ini mempunyai kelebihan dan kekurangan masingmasing.

Dari latar belakang tersebut penulis tertarik mencoba membandingkan sistem kerja pengiriman data dengan teknologi JSN menggunakan modul Xbee dan Wemos dimana data sensor suhu atau termokopel yang menjadi sampel data input dalam pengiriman data ini . Hasil dari penelitian dapat digunakan oleh masyarakat sebagai salah satu referensi dalam memilih modul wireless apa yang cocok untuk keperluan yang dibutuhkan dalam membangun jaringan sensor nirkabel.

\section{TEORI DASAR}

\section{Jaringan Sensor Nirkabel (JSN)}

Secara umum Jaringan Sensor Nirkabel (JSN) didefenisikan sebagai salah satu jenis dari jaringan Wireless (Nirkabel) terdistribusi yang menfaatkan teknologi Embedded system (sistem benam) dan perangkat node sensor,untuk melakukan proses sensor, monitoring, pengiriman, data dan penyajian informasi kepengguna, melalui komunikasi di internet. Sensor meliputi banyak jenis, antara lain kelembaban, radiasi, temperature, tekanan, mekanik, gerakan, getaran, posisi, dan lain-lain. Setiap jenis sensor memiliki perangkat lunak (aplikasi, sisten operasi) dan perangkat keras masing-masing yang kemudian akan digabungkan dan dijalankan kedalam system Wireless Sensor Network (WSN) [3].

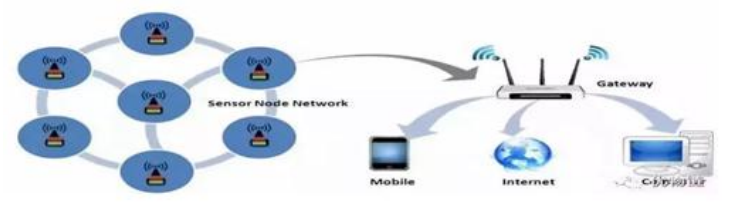

Gambar 1. Arsitektur Jaringan Nirkabel

\section{Wemos D1 Mini}

Wemos adalah sebuah microcontroller yang dikembangkan berbasis ESP8266. Microcontroller Wemos dibuat sebagai solusi dari mahalnya sebuah sistem Wireless berbasis microcontroller lainya. Dengan menggunakan microcontroller Wemos biaya yang dikerluarkan untuk membangun sistem microcontroller berbasis $\mathrm{WiFi}$ sangat mudah dan murah, biaya yang dikeluarkan apabila membangun sistem WiFi dengan menggunakna microcontroller Arduino Uno dan WiFi shiled. Wemos memiliki 2 versi yaitu Wemos D1 Mini dan Wemos D1 bentuk fisik dari Wemos sendiri dapat di lihat pada gambar 2.
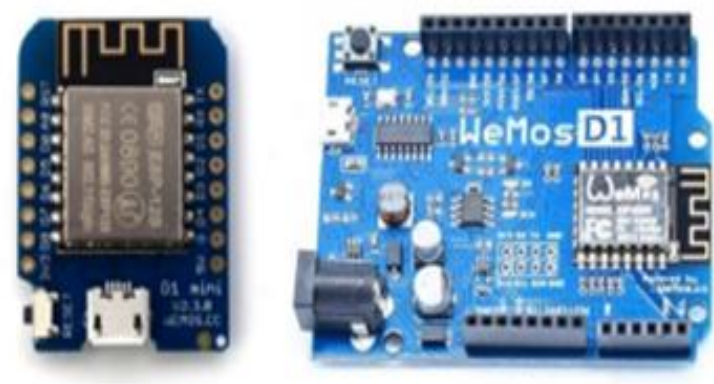

Gambar 2. Modul Wemos

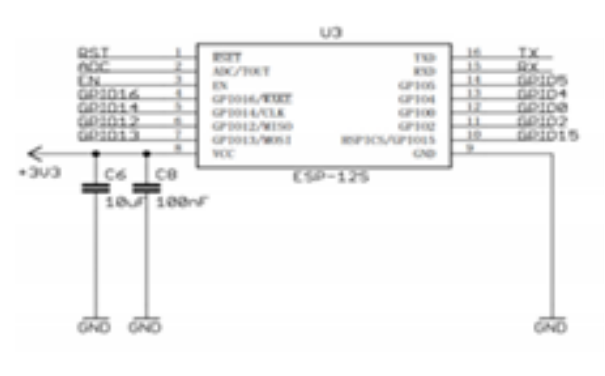

Gambar 3. Skematik Rangkaian ESP-12 Wemos D1 mini

Wemos D1 Mini merupakan board microcontroller open source yang menggunakan ESP-12S sebagai microcontrollernya Wemos memiliki 12 pin input /output, 1 pin digunakan untuk analog input maksimal 3.2V, 11 pin sisanyadigunakan untuk digital input / output. Lalu juga terdapat tombol reset, koneksi USB dengan kabel data micro USB dapat dilihat pada skematik rangkaian ESP-12S [4].

\section{Xbee Pro $\mathrm{S} 2$}

Modul RF XBee Pro S2 merupakan perangkat yang berfungsi sebagai protokol komunikasi nirkabel. Perangkat wireless yang membutuhkan daya rendah ini cocok untuk implementasi pada jaringan sensor nirkabel karena harganya yang relatif murah. Modul yang beroperasi pada frekuensi band ISM (Industrial, Scientific \& Medical) 2,4 GHz ini menyajikan kemampuan untuk pengiriman data antar perangkat dengan kemampuan kisaran jarak yang bervariasi tergantung pada kondisi dan tempat (indoor \& outdoor). Spesifikasi protokol Xbee Pro ini disiapkan untuk aplikasi yang memerlukan kecepatan data dan konsumsi daya rendah.

Perangkat ini memiliki 20 pin dengan fungsi yang berbeda-beda. Untuk koneksi minimum, dibutuhkan pin VCC, GND, DOUT \& DIN. Sedangkan untuk dapat melakukan update firmware, dibutuhkan koneksi pin VCC, GND, DIN, DOUT, RTS \& DTR. VCC dan GND untuk tegangan suplai, DOUT merupakan pin Transmit (TX), DIN 
merupakan pin Receive (RX), RESET merupakan pin reset XBee PRO dan yang terakhir adalah PWMO/RSSI merupakan indikator bahwa ada penerimaan data yang biasanya dihubungkan ke led yang di-drive oleh transistor. Untuk mengaktifkan XBee dibutuhkan supply tegangan sebesar $3.3 \mathrm{~V}$. XBee merupakan modul tranceiver, dengan mekanisme pengiriman data secara serial. Pin-pin untuk mengirim dan menerima data ada di pin 2 sebagai pin data OUT (Tx) dan pin 3 sebagai pin data IN (Rx). sehingga sangat penting untuk mengetahui pin Tx dan Rx [5]. Bentuk fisik dan konfigurasi pin XBee Pro S2 ditunjukkan pada gambar 4.
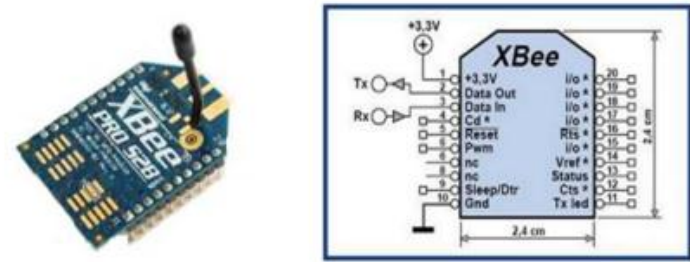

Gambar 4. Modul Xbee Pro S2

\section{Termokopel Tipe $\mathrm{K}$}

Termokopel (Thermocouple) merupakan sensor temperatur yang bisa digunakan mengukur suhu dengan nilai yang tinggi, sehingga sensor suhu Termokopel ini banyak digunakan untuk industri, sensor suhu termokopel memiliki nilai output yang kecil dengan noise yang tinggi, sehingga memerlukan rangkaian pengkodisian sinyal agar nilai output tersebut dapat dibaca dengan baik. Termokopel tipe K (campuran Crome / Alumel) sensor tipe ini banyak digunakan karena harganya yang murah, peka dan jangkauan temperatur yang luas yaitu dari $0^{\circ} \mathrm{C}$ sampai $+1100^{\circ} \mathrm{C}[6]$.

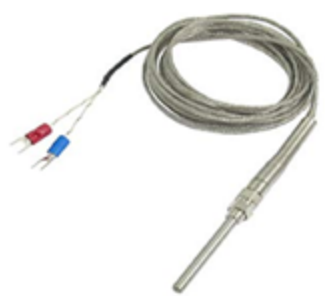

Gambar 5. Sensor Termokopel

\section{METODE PENELITIAN}

Metode yang digunakan dalam penelitian ini adalah metode eksperimental dan comperative testing, yaitu melakukan perancangan sistem dan alat, kemudian melakukan pengujian pada sistem yang dibangun dan dibandingkan antara hasil pengujian dengan sistem yang diharapkan.

Mekanisme kerja dari alat yang dirancang digambarkan melalui arsitektur perancangan sistem seperti yang diperlihatkan pada gambar 6 untuk arsitektur modul Xbee dan gambar 7 untuk arsitektur Wemos :

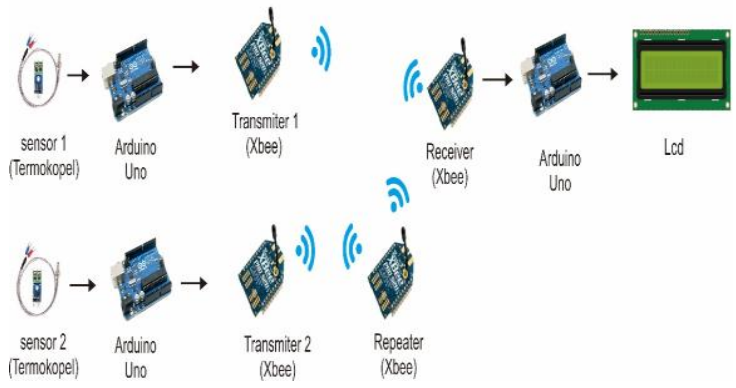

Gambar 6. Arsitektur Perancangan Sistem Xbee

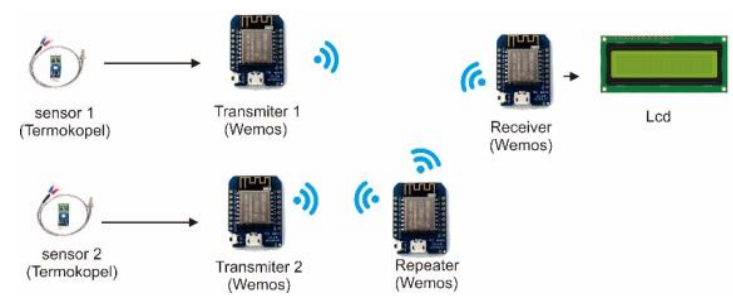

Gambar 7. Arsitektur Perancangan Sistem Wemos

Alat ini dirancang dan dibuat sedemikian rupa agar dapat melihat kinerja antara Xbee dan Wemos dalam hal pengiriman data dengan mengukur satu parameter yaitu suhu dengan menggunakan sensor utama yaitu sensor termokopel pada suhu minyak goreng yang dipanaskan. Sensor tersebut dihubungkan pada Arduino Uno yang mengubah Data sensor suhu yang berupa tegangan menjadi data digital dan terhubung dengan Modul Xbee atau Modul Wemos transmitter yang kemudian akan mengirim data tersebut ke Modul Xbee atau Modul Wemos Receiver yang dihubungkan dengan Mikrokontroller Arduino dan akan menerima data hasil pengukuran.data tersebut lalu di olah oleh Mikrokontroler Arduino ditampilkan pada LCD. Selain itu komponen yang banyak mendukung dalam sistem pada penelitian ini adalah mikrokontroller Arduino Uno yang berfungsi sebagai otak dari sistem yang mengatur semua komponen utama dari perangkat dan juga I/O dari sistem ini agar semuanya berjalan teratur dan dapat berfungsi sebagaimana mestinya.

\section{HASIL DAN PEMBAHASAN}

Pada hasil rancangan perangkat keras terdapat dua jenis alat yang telah dibuat yaitu hasil rancangan perangkat keras Modul Xbee dan Modul Wemos.

A. Hasil Rancangan Perangkat Keras Modul Xbee

Terdapat dua hasil rancangan modul Xbee yaitu hasil rancangan untuk jalur pertama dan hasil rancangan untuk jalur kedua. Hasil rancangan jalur pertama hanya terdapat termokopel, Modul Xbee transmitter, Modul Xbee Receiver, Arduino Uno dan LCD sedangkan Jalur kedua memiliki perbedaan dengan jalur pertama yaitu Xbee Repeater. 


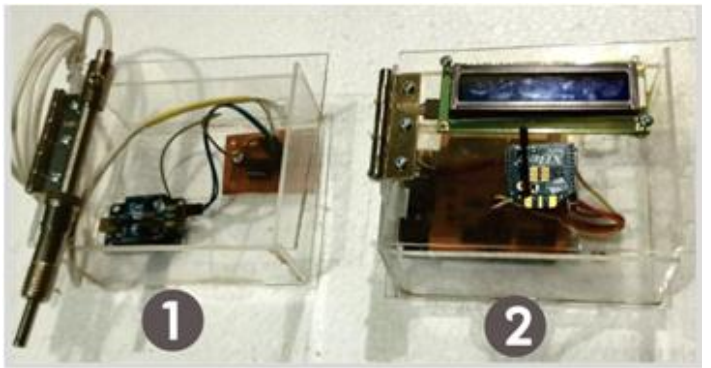

Gambar 8. Hasil Rancangan Xbee Jalur 1

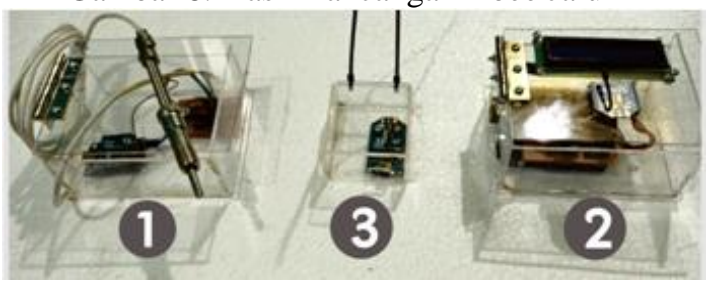

Gambar 9. Hasil Rancangan Xbee Jalur 2

Berdasarkan gambar rangkaian di atas, maka dapat diberikan keterangan sebagai berikut :

1). Terdapat termokopel untuk mengukur suhu, Arduino Uno yang akan mengubah data Sensor suhu yang berupa data tegangan ke data digital dan Xbee transmitter untuk mengirim data ke Xbee Receiver.

2). Terdapat Xbee Receiver yang menerima data dari Xbee Transmitter, selanjutnya terdapat Arduino Uno yang mengelola data dari Xbee Receiver untuk ditampilkan pada LCD sebagai output.

3). Terdapat Xbee Repeater untuk menerima data dari Xbee Transmitter dan selanjutnya dikirim ke Xbee Receiver.

B. Hasil Rancangan Perangkat Keras Modul Wemos

Terdapat dua hasil rancangan modul Wemos yaitu hasil rancangan untuk jalur pertama dan hasil rancangan untuk jalur kedua. Hasil rancangan jalur pertama hanya terdapat termokopel, Modul Wemos transmitter, Modul Wemos Receiver, dan LCD sedangkan Jalur kedua memiliki perbedaan dengan jalur pertama yaitu Xbee Repeater, seperti yang terlihat pada gambar 10 dan 11 .

Berdasarkan gambar rangkaian di atas, maka dapat diberikan keterangan sebagai berikut :

1). Terdapat termokopel untuk mengukur suhu, dan Wemos transmitter untuk mengirim data ke Wemos receiver.

2). Terdapat Wemos Receiver yang menerima data dari Wemos Transmitter untuk ditampilkan ke LCD sebagai output.

3). Teradapat Wemos Repeater Untuk menerima data dari Wemos Transmitter dan selanjutnya dikirim ke Wemos Receiver.

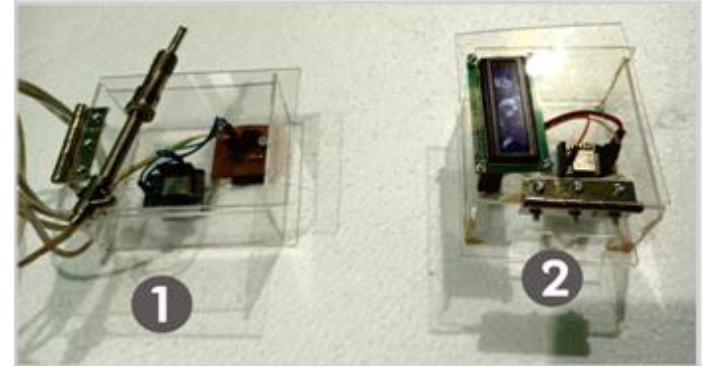

Gambar 10. Hasil Rancangan Wemos Jalur 1



Gambar 11. Hasil Rancangan Wemos Jalur 2

Untuk mengetahui apakah alat yang dibuat terdapat kesalahan atau tidak maka dilakukan pengujian. Adapun pengujian yang dilakukan dengan menguji secara keseluruhan kinerja alat. Bentuk pengujian pengiriman data seperti yang terlihat pada gambar 12 untuk modul Xbee dan gambar 13 untuk modul Wemos.

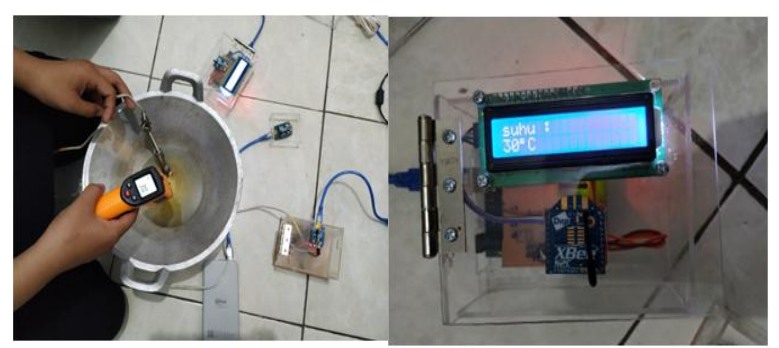

Gambar 12. Pengujian Pengiriman data menggunakan Modul Xbee

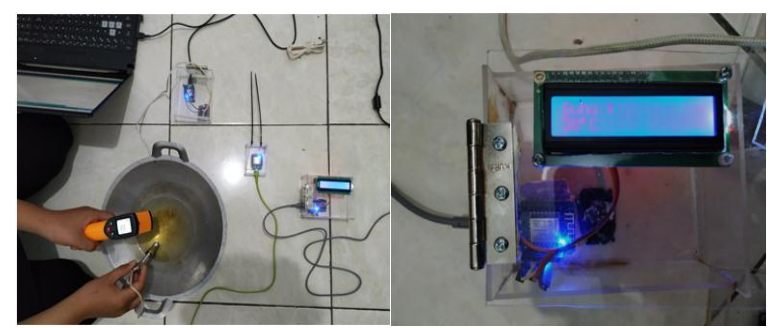

Gambar 13. Pengujian Pengiriman Data menggunakan Modul Wemos

A. Hasil Pengujian Pengiriman Data pada modul Xbee dan Wemos pada Kondisi LOS (Line Of Sight)

Pengujian ini bertujuan untuk mengetahui kemampuan jangkauan area Modul Xbee dan Modul Wemos dalam melakukan penerimaan data. Pengujian dilakukan diluar ruangan tanpa ada penghalang (obstacle). 
Pengujian pertama yaitu pengujian jarak jangkauan modul Xbee pada kondisi LOS tanpa repeater dengan data input suhu sebesar $30^{\circ} \mathrm{C}$. Untuk hasil pengukuran dan pengamatan jangkauan dapat dilihat pada tabel 1. Dari tabel 1 dapat disimpulkan bahwa data suhu dapat diterima pada jarak jangkauan maksimal 140 meter dengan delay 5 detik.

Tabel 1. Hasil Pengujian Jarak Jangkauan Modul

Xbee pada kondisi LOS tanpa Repeater (Jalur 1)

\begin{tabular}{|c|c|c|c|c|}
\hline Pengujian & $\begin{array}{c}\text { Data } \\
\text { Input } \\
\text { (Suhu) }\end{array}$ & $\begin{array}{c}\text { Jarak } \\
\text { (Meter) }\end{array}$ & $\begin{array}{c}\text { Delay } \\
\text { (Detik) }\end{array}$ & $\begin{array}{c}\text { Output } \\
\text { LCD }\end{array}$ \\
\hline 1 & $30^{\circ} \mathrm{C}$ & 10 & - & $30^{\circ} \mathrm{C}$ \\
\hline 2 & $30^{\circ} \mathrm{C}$ & 20 & - & $30^{\circ} \mathrm{C}$ \\
\hline 3 & $30^{\circ} \mathrm{C}$ & 30 & - & $30^{\circ} \mathrm{C}$ \\
\hline 4 & $30^{\circ} \mathrm{C}$ & 40 & - & $30^{\circ} \mathrm{C}$ \\
\hline 5 & $30^{\circ} \mathrm{C}$ & 50 & - & $30^{\circ} \mathrm{C}$ \\
\hline 6 & $30^{\circ} \mathrm{C}$ & 60 & - & $30^{\circ} \mathrm{C}$ \\
\hline 7 & $30^{\circ} \mathrm{C}$ & 70 & - & $30^{\circ} \mathrm{C}$ \\
\hline 8 & $30^{\circ} \mathrm{C}$ & 80 & - & $30^{\circ} \mathrm{C}$ \\
\hline 9 & $30^{\circ} \mathrm{C}$ & 90 & - & $30^{\circ} \mathrm{C}$ \\
\hline 10 & $30^{\circ} \mathrm{C}$ & 100 & - & $30^{\circ} \mathrm{C}$ \\
\hline 11 & $30^{\circ} \mathrm{C}$ & 110 & - & $30^{\circ} \mathrm{C}$ \\
\hline 12 & $30^{\circ} \mathrm{C}$ & 120 & - & $30^{\circ} \mathrm{C}$ \\
\hline 13 & $30^{\circ} \mathrm{C}$ & 130 & 4 & $30^{\circ} \mathrm{C}$ \\
\hline 14 & $30^{\circ} \mathrm{C}$ & 140 & 5 & $30^{\circ} \mathrm{C}$ \\
\hline 15 & $30^{\circ} \mathrm{C}$ & 150 & - & - \\
\hline 16 & $30^{\circ} \mathrm{C}$ & 160 & - & - \\
\hline
\end{tabular}

Selanjutnya hasil pengujian jarak Modul Xbee pada kondisi LOS menggunakan Repeater dengan data input suhu sebesar $30^{\circ} \mathrm{C}$ dapat dilihat pada tabel 2.

Tabel 2. Hasil Pengujian Jarak Jangkauan Modul

Xbee pada kondisi LOS menggunakan Repeater

(Jalur 2)

\begin{tabular}{|c|c|c|c|c|}
\hline Pengujian & $\begin{array}{c}\text { Data } \\
\text { Input } \\
\text { (Suhu) }\end{array}$ & $\begin{array}{c}\text { Jarak } \\
\text { (Meter) }\end{array}$ & $\begin{array}{c}\text { Delay } \\
\text { (Detik) }\end{array}$ & $\begin{array}{c}\text { Output } \\
\text { LCD }\end{array}$ \\
\hline 1 & $30^{\circ} \mathrm{C}$ & 20 & - & $30^{\circ} \mathrm{C}$ \\
\hline 2 & $30^{\circ} \mathrm{C}$ & 40 & - & $30^{\circ} \mathrm{C}$ \\
\hline 3 & $30^{\circ} \mathrm{C}$ & 60 & - & $30^{\circ} \mathrm{C}$ \\
\hline 4 & $30^{\circ} \mathrm{C}$ & 80 & - & $30^{\circ} \mathrm{C}$ \\
\hline 5 & $30^{\circ} \mathrm{C}$ & 100 & - & $30^{\circ} \mathrm{C}$ \\
\hline 6 & $30^{\circ} \mathrm{C}$ & 120 & - & $30^{\circ} \mathrm{C}$ \\
\hline 7 & $30^{\circ} \mathrm{C}$ & 140 & - & $30^{\circ} \mathrm{C}$ \\
\hline 8 & $30^{\circ} \mathrm{C}$ & 160 & - & $30^{\circ} \mathrm{C}$ \\
\hline 9 & $30^{\circ} \mathrm{C}$ & 180 & - & $30^{\circ} \mathrm{C}$ \\
\hline 10 & $30^{\circ} \mathrm{C}$ & 200 & - & $30^{\circ} \mathrm{C}$ \\
\hline 11 & $30^{\circ} \mathrm{C}$ & 220 & - & $30^{\circ} \mathrm{C}$ \\
\hline 12 & $30^{\circ} \mathrm{C}$ & 240 & - & $30^{\circ} \mathrm{C}$ \\
\hline 13 & $30^{\circ} \mathrm{C}$ & 260 & 5 & $30^{\circ} \mathrm{C}$ \\
\hline 14 & $30^{\circ} \mathrm{C}$ & 280 & 6 & $30^{\circ} \mathrm{C}$ \\
\hline 15 & $30^{\circ} \mathrm{C}$ & 300 & - & - \\
\hline & & & & \\
\hline
\end{tabular}

\begin{tabular}{|l|l|l|l|l|}
\hline 16 & $30^{\circ} \mathrm{C}$ & 320 & - & - \\
\hline
\end{tabular}

Dari hasil pengujian seperti yg terlihat pada tabel 2, data masih bisa diterima oleh LCD pada jarak jangkauan maksimal 280 meter dengan delay 6 detik pada kondisi LOS dengan menggunakan repeater.

Selanjutnya hasil pengujian Jarak Modul Wemos pada Kondisi LOS tanpa Repeater dengan Input data suhu sebesar $30^{\circ} \mathrm{C}$ seperti yang terlihat pada tabel 3 .

Tabel 3. Hasil Pengujian Jarak Jangkauan Modul

Wemos pada kondisi LOS tanpa Repeater (Jalur 1)

\begin{tabular}{|c|c|c|c|c|}
\hline Pengujian & $\begin{array}{c}\text { Data } \\
\text { Input } \\
\text { (Suhu) }\end{array}$ & $\begin{array}{c}\text { Jarak } \\
\text { (Meter) }\end{array}$ & $\begin{array}{c}\text { Delay } \\
\text { (Detik) }\end{array}$ & $\begin{array}{c}\text { Output } \\
\text { LCD }\end{array}$ \\
\hline 1 & $30^{\circ} \mathrm{C}$ & 10 & - & $30^{\circ} \mathrm{C}$ \\
\hline 2 & $30^{\circ} \mathrm{C}$ & 20 & - & $30^{\circ} \mathrm{C}$ \\
\hline 3 & $30^{\circ} \mathrm{C}$ & 30 & - & $30^{\circ} \mathrm{C}$ \\
\hline 4 & $30^{\circ} \mathrm{C}$ & 40 & - & $30^{\circ} \mathrm{C}$ \\
\hline 5 & $30^{\circ} \mathrm{C}$ & 50 & - & $30^{\circ} \mathrm{C}$ \\
\hline 6 & $30^{\circ} \mathrm{C}$ & 60 & 4 & $30^{\circ} \mathrm{C}$ \\
\hline 7 & $30^{\circ} \mathrm{C}$ & 70 & 5 & $30^{\circ} \mathrm{C}$ \\
\hline 8 & $30^{\circ} \mathrm{C}$ & 80 & - & - \\
\hline
\end{tabular}

Dari tabel 3 dapat disimpulkan hasil pengujian jarak jangkauan pengiriman data Modul Wemos pada kondisi LOS Tanpa repeater yaitu maksimal 70 meter dengan delay 5 detik

Untuk hasil Pengujian Jarak Modul Wemos pada Kondisi LOS menggunakan Repeater dengan Input data suhu sebesar $30^{\circ} \mathrm{C}$.dapat dilihat pada tabel 4.

Tabel 4. Hasil Pengujian Jarak Jangkauan Modul Wemos pada kondisi LOS menggunakan Repeater (Jalur 2)

\begin{tabular}{|c|c|c|c|c|}
\hline Pengujian & $\begin{array}{c}\text { Data } \\
\text { Input } \\
\text { (Suhu) }\end{array}$ & $\begin{array}{c}\text { Jarak } \\
\text { (Meter) }\end{array}$ & $\begin{array}{c}\text { Delay } \\
\text { (Detik) }\end{array}$ & $\begin{array}{c}\text { Output } \\
\text { LCD }\end{array}$ \\
\hline 1 & $30^{\circ} \mathrm{C}$ & 20 & - & $30^{\circ} \mathrm{C}$ \\
\hline 2 & $30^{\circ} \mathrm{C}$ & 40 & - & $30^{\circ} \mathrm{C}$ \\
\hline 3 & $30^{\circ} \mathrm{C}$ & 60 & - & $30^{\circ} \mathrm{C}$ \\
\hline 4 & $30^{\circ} \mathrm{C}$ & 80 & - & $30^{\circ} \mathrm{C}$ \\
\hline 5 & $30^{\circ} \mathrm{C}$ & 100 & - & $30^{\circ} \mathrm{C}$ \\
\hline 6 & $30^{\circ} \mathrm{C}$ & 120 & 5 & $30^{\circ} \mathrm{C}$ \\
\hline 7 & $30^{\circ} \mathrm{C}$ & 140 & 7 & $30^{\circ} \mathrm{C}$ \\
\hline 8 & $30^{\circ} \mathrm{C}$ & 160 & - & - \\
\hline
\end{tabular}

Dari tabel 4 dapat disimpulkan hasil pengujian jarak jangkauan pengiriman data untuk Modul Wemos pada kondisi LOS menggunakan repeater yaitu maksimal 140 meter dengan delay 7 detik.

B. Hasil Pengujian Pengiriman Data modul Xbee dan Wemos pada kondisi NLOS (None Line Of Sight)

Pengujian ini bertujuan untuk mengetahui kemampuan jangkauan jarak Modul Xbee dan 
Modul Wemos dalam melakukan penerimaan data. Dari prosedur pengujian komunikasi data pada Modul Xbee/Wemos yang telah dilakukan di dalam ruangan (Kondisi NLOS) didapatkan hasil pengamatan jangkauan sebagai berikut :

Pengujian yang pertama yaitu pengujian jarak jangkauan Modul Xbee pada kondisi NLOS tanpa repeater dengan Input data suhu sebesar $30^{\circ} \mathrm{C}$. Hasil pengujian dapat dilihat pada tabel 5.

Dari tabel 5 dapat disimpulkan hasil pengujian jarak jangkauan pengiriman data untuk Modul Xbee pada kondisi NLOS tanpa repeater yaitu maksimal 25 meter dengan delay 6 detik.

Tabel 5. Hasil Pengujian Jarak Jangkauan Modul

Xbee pada kondisi NLOS tanpa Repeater (Jalur 1)

\begin{tabular}{|c|c|c|c|c|}
\hline Pengujian & $\begin{array}{c}\text { Data } \\
\text { Input } \\
\text { (Suhu) }\end{array}$ & $\begin{array}{c}\text { Jarak } \\
\text { (Meter) }\end{array}$ & $\begin{array}{c}\text { Delay } \\
\text { (Detik) }\end{array}$ & $\begin{array}{c}\text { Output } \\
\text { LCD }\end{array}$ \\
\hline 1 & $30^{\circ} \mathrm{C}$ & 5 & - & $30^{\circ} \mathrm{C}$ \\
\hline 2 & $30^{\circ} \mathrm{C}$ & 10 & - & $30^{\circ} \mathrm{C}$ \\
\hline 3 & $30^{\circ} \mathrm{C}$ & 15 & 3 & $30^{\circ} \mathrm{C}$ \\
\hline 4 & $30^{\circ} \mathrm{C}$ & 20 & 5 & $30^{\circ} \mathrm{C}$ \\
\hline 5 & $30^{\circ} \mathrm{C}$ & 25 & 6 & $30^{\circ} \mathrm{C}$ \\
\hline 6 & $30^{\circ} \mathrm{C}$ & 30 & - & - \\
\hline
\end{tabular}

Selanjutnya Hasil Pengujian Jarak Modul Xbee pada Kondisi NLOS menggunakan Repeater dengan Input data suhu sebesar $30^{\circ} \mathrm{C}$ dapat dilihat pada tabel 6 .

Tabel 6. Hasil Pengujian Jarak Jangkauan Modul Xbee pada kondisi NLOS menggunakan Repeater

\begin{tabular}{|c|c|c|c|c|}
\hline Pengujian & $\begin{array}{c}\text { Data } \\
\text { Input } \\
\text { (Suhu) }\end{array}$ & $\begin{array}{c}\text { Jarak } \\
\text { (Meter) }\end{array}$ & $\begin{array}{c}\text { Delay } \\
\text { (Detik) }\end{array}$ & $\begin{array}{c}\text { Output } \\
\text { LCD }\end{array}$ \\
\hline 1 & $30^{\circ} \mathrm{C}$ & 10 & - & $30^{\circ} \mathrm{C}$ \\
\hline 2 & $30^{\circ} \mathrm{C}$ & 20 & - & $30^{\circ} \mathrm{C}$ \\
\hline 3 & $30^{\circ} \mathrm{C}$ & 30 & - & $30^{\circ} \mathrm{C}$ \\
\hline 4 & $30^{\circ} \mathrm{C}$ & 40 & 3 & $30^{\circ} \mathrm{C}$ \\
\hline 5 & $30^{\circ} \mathrm{C}$ & 50 & 6 & $30^{\circ} \mathrm{C}$ \\
\hline 6 & $30^{\circ} \mathrm{C}$ & 60 & - & - \\
\hline \multicolumn{7}{|c}{ Dari tabel 6 dapat disimpulkan hasil } \\
\hline
\end{tabular}
pengujian jarak jangkauan pengiriman data untuk Modul Xbee pada kondisi NLOS menggunakan repeater yaitu maksimal pada jarak 50 meter dengan delay 6 detik.

Untuk hasil pengujian Jarak jangkauan Modul Wemos pada Kondisi NLOS tanpa Repeater dengan Input data suhu sebesar $30^{\circ}$ dapat dilihat pada tabel 7 .

Tabel 7. Hasil Pengujian Jarak Jangkauan Modul Wemos pada kondisi NLOS tanpa Repeater (Jalur 1)

\begin{tabular}{|c|c|c|c|c|}
\hline Pengujian & $\begin{array}{c}\text { Data } \\
\text { Input } \\
\text { (Suhu) }\end{array}$ & $\begin{array}{c}\text { Jarak } \\
\text { (Meter) }\end{array}$ & $\begin{array}{c}\text { Delay } \\
\text { (Detik) }\end{array}$ & $\begin{array}{c}\text { Output } \\
\text { LCD }\end{array}$ \\
\hline 1 & $30^{\circ} \mathrm{C}$ & 5 & - & $30^{\circ} \mathrm{C}$ \\
\hline 2 & $30^{\circ} \mathrm{C}$ & 10 & - & $30^{\circ} \mathrm{C}$ \\
\hline
\end{tabular}

\begin{tabular}{|c|c|c|c|c|}
\hline 3 & $30^{\circ} \mathrm{C}$ & 15 & - & $30^{\circ} \mathrm{C}$ \\
\hline 4 & $30^{\circ} \mathrm{C}$ & 20 & - & - \\
\hline
\end{tabular}

Hasil pengujian pada tabel 7 dapat disimpulkan jarak jangkauan pengiriman data untuk modulWemos pada kondisi NLOS tanpa repeater yaitu maksimal 15 meter.

Selanjutnya Hasil Pengujian Jarak Modul Wemos pada Kondisi NLOS menggunakan Repeater dengan Input data suhu sebesar $30^{\circ} \mathrm{C}$ seperti yang terlihat pada tabel 8 .

Dari tabel 8 dapat disimpulkan hasil pengujian jarak jangkauan Modul Wemos pada kondisi NLOS menggunakan repeater yaitu 30 meter dimana pada jarak 30 meter data yang dikirim masih bisa diterima tetapi terdapat delay sebesar 3 detik.

Tabel 8. Hasil Pengujian Jarak Jangkauan Modul Wemos pada kondisi NLOS menggunakan Repeater (Jalur 2)

\begin{tabular}{|c|c|c|c|c|}
\hline Pengujian & $\begin{array}{c}\text { Data } \\
\text { Input } \\
\text { (Suhu) }\end{array}$ & $\begin{array}{c}\text { Jarak } \\
\text { (Meter) }\end{array}$ & $\begin{array}{c}\text { Delay } \\
\text { (Detik) }\end{array}$ & $\begin{array}{c}\text { Output } \\
\text { LCD }\end{array}$ \\
\hline 1 & $30^{\circ} \mathrm{C}$ & 10 & - & $30^{\circ} \mathrm{C}$ \\
\hline 2 & $30^{\circ} \mathrm{C}$ & 20 & - & $30^{\circ} \mathrm{C}$ \\
\hline 3 & $30^{\circ} \mathrm{C}$ & 30 & 3 & $30^{\circ} \mathrm{C}$ \\
\hline 4 & $30^{\circ} \mathrm{C}$ & 40 & - & - \\
\hline
\end{tabular}

Setelah dilakukan pengujian dengan berbagai kondisi dengan hasil seperti yang terlihat pada tabel 1 sampai 8 maka kelihatan jelas bahwa fungsi repeater sebagai penguat sinyal sangat membantu dalam hal menambah jarak jangkauan pengiriman data menggunakan Jaringan Sensor Nirkabel (JSN) khususnya untuk moduk Xbee dan Wemos serta pada kondisi NLOS (None Line Of Sight), penghalang (obstacle) menjadi salah satu faktor dalam mengurangi jarak jangkauan karena sinyal yang dikirim terpantul atau bahkan terserap tergantung jenis penghalang yang ada seperti pohon, rumah ataupun gedung sehingga menyebabkan adanya delay dalam pengiriman data.

\section{KESIMPULAN}

Berdasarkan hasil analisis pengujian terhadap Modul Xbee Dan Modul Wemos dalam pengiriman data Jaringan Sensor Nirkabel maka dapat diambil kesimpulan sebagai berikut Pengiriman Data Jaringan Sensor Nirkabel menggunakan suhu minyak goreng yang dipanaskan sebagai sampel data yang dideteksi oleh sensor termokopel dapat dijadikan sumber data pengujian kinerja Modul Xbee dan Wemos. Hasil Pengujian, Jarak Maksimal pengiriman data pada kondisi LOS (line Of Sight) tanpa repeater untuk modul Xbee yaitu 140 meter dengan delay 5 detik sedangkan modul Wemos yaitu 70 meter dengan delay 5 detik. Sedangkan jarak maksimal pada kondisi LOS dengan menggunakan repeater untuk modul Xbee yaitu 280 meter dengan delay 6 detik dan modul Wemos yaitu 140 meter 
dengan delay 7 detik. Hasil Pengujian Jarak Maksimal pengiriman data pada kondisi NLOS (None line Of Sight) tanpa repeater untuk modul Xbee yaitu 25 meter dengan delay 6 detik sedangkan modul Wemos yaitu 15 meter. Sedangkan jarak maksimal pada kondisi NLOS dengan menggunakan repeater untuk modul Xbee yaitu 50 meter dengan delay 6 detik dan modul Wemos yaitu 30 meter. Pengiriman data menggunakan Modul Xbee memiliki jangkauan jarak yang lebih jauh dibandingkan dengan modul Wemos baik dalam kondisi LOS (Line on sight) ataupun NLOS (None Line on Sight).

\section{DAFTAR PUSTAKA}

[1] Perdana, C., Ahmad, T., \& Shiddiqi, M. (2013). Pembangunan Jaringan Sensor Nirkabel Berprotokol, 2(1), 2-5.

[2] Hartawan, I. N. B., \& Desnanjaya, I. G. M. N. (2018). Analisis Kinerja Protokol Zigbee Di Dalam Dan Di Luar Ruangan Sebagai Media Komunikasi Data Pada Wireless Sensor Network. Jurnal RESISTOR (Rekayasa Sistem Komputer), 1(2), 65-72.

[3] Pratama, I.P.A,\& Suakanto, S. (2015). Wireless Sensor Network. Informatika. Bandung.

[4] Utomo, D. S. (2018). Product Price Display Using Wemos Tugas Akhir.

[5] Fajriansyah, B., Ichwan, M., \& Susana, R. (2018). Evaluasi Karakteristik XBee Pro dan nRF24L01+ sebagai Transceiver Nirkabel. ELKOMIKA: Jurnal Teknik Energi Elektrik, Teknik Telekomunikasi, \& Teknik Elektronika, 4(1), 83 .

[6] Effendrik, P., Joelianto, G., \& Sucipto, H. (n.d.). (2014). Karakterisasi Thermocouple Dengan Menggunakan Perangkat Lunak Matlab Simulink, 133-145. 